\title{
Can Beliefs be Based on Practical Reasons?
}

Miriam Schleifer McCormick

For Well Founded Belief: New Essays on the Epistemic Basing Relation, edited by Pat Bondy and J. Adam Carter (Routledge, 2019, 215-234). Please cite published (and corrected) version.

The claim that there are no practical reasons for belief is one commonly made by theorists of reasons and belief. In thinking about different kinds of reasons, some will say there are those that pertain to belief (called epistemic or theoretical) and those pertaining to action (called practical), and that these are completely exclusive domains. ${ }^{1}$ To get a grasp of the difference between an epistemic reason and a non-epistemic reason for belief, consider two different kinds of reasons I can have for the belief that my child will awaken from the general anesthetic he was given. The first appeals to the statistics and probabilities that support the truth of the proposition related to the belief in a straightforward way. The second appeals to the value of having the belief; having this belief provides me with peace of mind, allows me to care for my other children and for my child to have his required surgery.

When the claim that there are no practical reasons for belief is developed or defended, it is usually modified so that what is being denied is the possibility of a quite specific phenomenon. All will admit that practical considerations, in fact, can contribute causally to what one believes. Many will even say that such considerations can count as reasons for these subjects to believe and, again, such reasons may partially cause the beliefs. What they deny, however, is that these non-evidential reasons are reasons for which these subjects believe; beliefs, they say, cannot be based on such reasons. ${ }^{2}$ Exactly what relation between reason and belief is captured by the expression "for which" or "basis" that goes beyond the mere causal is controversial and much of the work in this volume is devoted to clarifying this relation. To get the idea of a consideration that is the cause of a belief but not one that the belief is based on consider the difference between the following cases:

\footnotetext{
${ }^{1}$ See Derek Parfit's (2001) very influential discussion on this point. He says "Practical and epistemic reasons are always quite different" though they can be related in important ways. Nomy Arpaly has recently argued that we have no practical reasons to believe: "It is a category mistake to talk about practical reasons to believe." (6)

${ }^{2}$ In some discussions of the basing relation, reasons for which we $\mathrm{X}$ are also referred to as motivating reasons. For example, Keshav Singh (2018) begins his recent paper by saying "Motivating reasons are the reasons for which we $\phi$. These reasons are also sometimes said to be the reasons in light of which, or the reasons on the basis of which, we act, believe and so on." Other theorists have some qualms talking about motivating reasons for belief because it makes belief seem to be too action-like. Can I have a motivating reason to be in a state? I will mostly avoid talking in terms of motivating reasons, but when I do, I will, like Singh, take them to be equivalent to the reasons for which one believes.
} 
Sam's reason for believing that Billy is kind is that he gives to Oxfam. Lois's reasons for believing that the paper should be accepted are the paper's excellent ideas and examples. Sam and Lois differ from Jean, whose belief that Abuja is the capital of Nigeria was caused by a blow to the head. While there is a reason why Jean believes what she does (i.e., an explanatory reason), there are no reasons for which she believes what she does (i.e., no motivating reasons). ${ }^{3}$

Given that this volume concerns the "epistemic basing relation," if these domains really are completely distinct then one may think it follows trivially that beliefs cannot be epistemically based on practical reasons. Here are two examples representing the view that beliefs cannot be based on practical reasons:

"Although practical considerations can make a difference to what one believes, they do not do so by constituting grounds on which beliefs are based....And rational beliefs, like rational actions, are rationalized by those considerations on which they are based." (Kelly, 2002)

"Necessarily, if $S$ takes $r$ to be a practical reason $S$ has to believe $p$, then $S$ does not believe that $p$ on the basis of $r$." (Comesaña, 2015)

To answer the title question fully, it needs to be divided into two separate questions. The first is: Can one take oneself to believe for practical reasons? I will argue that the most plausible characterizations of the basing relation do not rule this out. What is centrally involved in basing a belief on a reason is that one treats the relation as a justificatory one, that one endorses the connection between the reason and the belief. The further question is: Can this endorsement or representation be correct, proper or rational? Since many take the answer to the first question to be "No," the second question never gets asked. My answer to the second question is also "yes"; one can distinguish between good and bad cases of believing for practical reasons just as one can distinguish between good and bad cases as believing for evidential ones. To make room for the idea that practical reasons can justify, however, requires de-linking doxastic justification from propositional, taking seriously a point made by Derek Piller (2001) that "logic is only indirectly related to theories of reasoning" (200).

\section{Can beliefs be based on practical reasons?}

\footnotetext{
${ }^{3}$ Sylvan and Lord begin their paper (this volume) by distinguishing these cases. They argue that to understand what it means for a belief to be based on a sufficient normative reason requires more than the reason being both motivating and a good normative one. It is possible for each of those conditions to met, without the appropriate relation holding between it being motivating and being a good reason. They argue instead that this relation cannot be reduced to parts that obtain independently of each other.
} 
To assess whether it is the case that there is a whole class of reasons on which beliefs cannot be based, we need some understanding of the basing relation. But providing a characterization of this relation has proved extremely difficult, though there is much recent (and current) work being done trying to clarify it. It should be noted that, for epistemologists, the motivation to gain a clearer understanding of the basing relation is usually that doing so will help us understand what kind of relationship is required between a belief and a reason so that one is doxastically justified in holding the belief. Often these discussions assume that there are reasons that count in favor of the proposition believed (and this is termed "propositional justification") but for the attitude of belief to be justified by this reason, it must be based on this reason, but what does it mean to be so based? ${ }^{4}$

As noted, the relationship cannot be simply causal as many causes of beliefs may not be reasons at all, let alone reasons for which one believes. As Keith Korcz puts it "given that in principle anything can cause anything, a causal account of the basing relation will allow beliefs to be based on reasons which seem completely unrelated to them. For instance, one's belief about having ridden a zebra once might, in principle, cause one to believe that Queen Elizabeth was a member of the Mafia." $(2000,545)$ In attempts to provide an account of the relation, some stick to a general causal story but try to articulate the appropriate kind of causation so as to rule out deviant causal chains while others have abandoned that approach in favor of what are sometimes termed "doxastic" accounts which state that a belief is only based on a reason if one has a metabelief that the belief is so based. ${ }^{5}$ Still others are searching for an alternative which avoids the pitfalls and retain the virtues of both the causal approach and the doxastic ones. ${ }^{6}$

These alternative or hybrid approaches attempt to articulate what the agent's attitude who is basing the belief on the reason must be. The problem with simple causal accounts is they say nothing about the agent's perspective or attitude. Doxastic accounts try to remedy this but in doing so overly intellectualize the requirement. If one needs to believe that a particular consideration is the normative reason for which one believes, this would seem to imply that children or animals could not base their beliefs on reasons. It seems to require that one have quite sophisticated concepts like "normative reason." Further, one may wonder if one needs to have meta-beliefs about those meta-

\footnotetext{
${ }^{4}$ The distinction is also sometimes made in terms of a belief being justifiable and beliefs being justified. This is, for example, how Korcz (2000) introduces his discussion. For helpful discussion of what the relation is trying to identify see also McCain (2012) and Neta (ms)

${ }^{5}$ For a useful overview of more complex causal accounts see Sylvan (2016)

${ }^{6}$ Ram Neta (ms), Kurt Sylvan (2016) and Keshav Singh (2018) are among those who are trying to articulate an alternative theory.
} 
beliefs, and further meta-meta beliefs, leading to an infinite regress of higher order beliefs. ${ }^{7}$ Stephanie Leary (2016) suggests that we label the cognitive attitude one adopts towards the reason and its relation to one's belief as "conceiving."

So, let's use the phrase conceiving of $r$ as a reason to $\varphi$ as a stipulative term that refers to whatever cognitive element is involved in $\varphi$ ng for a reason, and simply claim that in order for $\mathrm{R}$ to be a reason for which one $\varphi$ s one must be disposed to $\varphi$ because one conceives $R$ as reason to $\varphi$... And I will assume here that believing $\mathrm{R}$ is a reason to $\varphi$ is sufficient, but may not be necessary for conceiving $R$ as a reason to $\varphi$. (8)

She does not offer any precision about what it takes to conceive in this way, and she does not need to for the main point of her argument, but the examples she provides suggest that it requires a conscious endorsement of $r$ being a reason. Believing for a reason, or basing a belief on reason does not, however, always seem to require that one has such awareness. It is common in accounts of the basing relation, to talk about "representing" a consideration as reason which, depending on the view, can allow for such representations to be less than fully conscious or explicitly endorsed. Ram Neta is quite explicit that one can represent a reason as justifying in the way required for it to be the reason for which one has a particular attitude without conscious recognition:

This account is consistent with the obvious fact that it is possible for an agent to $\mathrm{C}$ for the reason $\mathrm{R}$ even when she doesn't know what her reason for C'ing is: this is quite common for mature humans, and even more common for the less mature. There might be reasons for which I am angry at my parents, but I might not know what those reasons are: I can represent an explanatory relation even if I fail to represent some of its relata, just as I can represent a whole even if I fail to represent its parts. Also, my account of the basing relation is consistent with an agent's $C^{\prime}$ ing for the reason $R$ even when she also believes that $R$ is not a good reason for C'ing: my account explains why such cases involve a kind of incoherence on the part of the agent, who is both committed (by her basing relation) to $\mathrm{R}$ being a good reason for $\mathrm{C}^{\prime} \mathrm{ing}$, but also committed (by her beliefs) to $\mathrm{R}$ not being a good reason for $\mathrm{C}^{\prime} \mathrm{ing}$.

Kurt Sylvan (2016) characterizes this agential attitude required in the basing relation as "treating":

Treating something as a reason does not require having the concept of a reason. This is an instance of the more general thought that treating Xs as Fs doesn't require the concept of an F. Cats, for example, can treat entities as prey while lacking the concept PREY. Inferring $p$ from $q$ entails treating $q$ as a normative

\footnotetext{
${ }^{7}$ McCain (2016) brings up this objection, as well as many other problems with doxastic accounts in Chapter 7 .
} 
reason to believe $\mathrm{p}$, but does not require having or using the concept normative reason.

Others use the language of "taking" to describe the attitude needed in basing a belief on a reason, or inferring one belief from another. In trying to articulate what it means to take something to be evidence or to be a reason which distinguishes it from believing it to be evidence or a reason, Comesaña asks us to consider the question of what it means to take someone to be a scoundrel. He says "in a very clear way, believing that $S$ is a scoundrel is neither necessary nor sufficient for taking $S$ to be a scoundrel." You can act in ways which reveal that you take someone is a scoundrel and actually discover this to be the case without having the belief that he is a scoundrel. He proposes we "interpret takings not as full-fledged doxastic attitudes, but rather as motivational states that would be rationalized by the corresponding doxastic attitudes."

According to these views, then, for a belief to be based on reason requires that one "treat" or "take" the consideration as reason. Depending on the details of these accounts, treating or taking can be understood as a kind of complex disposition or representation, or a combination of both. ${ }^{8}$ And what is important is that someone treating a consideration as reason for believing figures in the explanation of why that person so believes.

Most such accounts do not rule out that one could treat a practical consideration as a reason. ${ }^{9}$ This is most obvious for those who allow that the treating condition need not even be consciously endorsed. Consider someone who believes that humans all have the capacity for good. On what reason would such a belief be based? Having such a belief is good for the person who has it and for those with whom the person interacts. The benefits of believing this way is one of the factors that sustains it and it is hard to see what would rule out treating in this way, as tacitly endorsing it as the answer to the question why do you believe? Thinking about tacit treating of evidential considerations as reasons for belief, ones that may even be explicitly disavowed, makes it even more clear that practical considerations cannot be ruled out as reasons for which one believes. We saw above that Neta's view clearly allows for this. He considers the case of Nyambi

${ }^{8}$ Boghossian (2014) canvasses different ways that we can understand the taking condition which he argues is necessary for reasoning from $\mathrm{p}$ to $\mathrm{q}$, or basing $\mathrm{q}$ on $\mathrm{p}$. He ultimately concludes that it is best understood as "following a rule in one's thought" but that the notion of following a rule is "an unanalyzable primitive." (17)

${ }^{9}$ Jonathan Way (2016) comes to the same conclusion. None of these accounts rule out that one can base one's belief on practical considerations if one allows that one can reason badly from such considerations. I discuss his argument for why practical reasons cannot be reasons for belief below. 
who claims that his reason for believing that the Russians bombed civilian targets in Syria is that he heard a news report of Al Jazeera when, in fact, he actually has "a disposition to believe everything he hears reported on CNN" and that he "(unbeknownst to him) exercises this disposition and thereby comes to believe that Russian forces have bombed civilian targets in Syria." In such a case Nyambi would represent the relation between "I heard it on Al Jazeera" and "I believe the Russian forces bombed civilian targets" in the way needed for it to be an example of basing his belief on that reason, but he would be mistaken in doing so: "Just as it is possible to represent the visible distance between two objects even when one is ignorant or mistaken about what those two objects are, so too is it possible to represent the explanatory relation between $\mathrm{R}$ and one's $\mathrm{C}^{\prime}$ ing, even when one is mistaken about what $\mathrm{R}$ and C are" (37)

In recent work Paul Boghossian (forthcoming) is clear that to "take" something as reason does not require conscious awareness, and that the "taking condition" which he argues is necessary for one to infer $\mathrm{q}$ from $\mathrm{p}$ can sometimes be tacit, and may not even be accessible to the agent. In quick, effortless reasoning it may seem that one is drawing inferences, or basing a belief on a reason without needing to take $\mathrm{p}$ to be a reason for $\mathrm{q}$. Susannah Siegel, for example says of the following that it is an inference without a taking condition, or what she calls inference without reckoning.

Pepperoni: Usually you eat three slices of pizza when it comes with pepperoni. But tonight, after eating one slice, you suddenly don't want any more. Struck by your own uncharacteristic aversion, you form the belief that the pizza is yucky. Though you don't know it, the factors include the facts that (i) the pepperoni tastes very salty to you, (ii) it looks greasy, (iii) it reminds you of someone you don't like, who you recently learned loves pepperoni, and (iv) you have suddenly felt the force of moral arguments against eating meat. If the next bites of pepperoni were less salty, the greasy appearance turned out to be glare from the lights, you learned that your nemesis now avoids pepperoni, and the moral arguments didn't move you, the conclusion of your inference would weaken, and so would your aversion. You haven't classified what you see and taste as: too greasy, too salty, reminiscent of your nemesis, or the sad product of immoral practices. Nor are you consciously thinking right now about any of these things. (forthcoming) ${ }^{10}$

\footnotetext{
${ }^{10}$ Nomy Arpaly and Timothy Schroeder (2014) have also brought to attention examples of reasoning without awareness or deliberation.
} 
Siegel argues that cases like this are inferences since your conclusion is epistemically dependent on the factors i-iv, and "you could have better or worse reasons for the conclusion..., and that would make the conclusion better or worse."

Boghossian replies that if it is a genuine inference then there must be a taking condition, however tacit. He thinks that there are number of good theoretical reasons for insisting on there being such a condition. I will mention two of them. First, he argues that without such a condition there is no way to differentiate between mere association and inference. He considers the example of the depressive who, on thinking "I am having so much fun" always then thinks "But there is so much suffering in the world." Such a person "is having an association of judgments on the basis of their content. But he is not thereby inferring from the one proposition to the other."(forthcoming) Now one of the differences between association and inference is that inference, or reasoning involves something you do and so allows you do be held responsible and appropriately criticized. He says that the taking condition offers a clear way of making "your reasoning count as agential" and for "your reasoning to be a process for which you could intelligibly be held rationally responsible."

We do not here need to adjudicate on who is right or about what makes something an inference or reasoning, as opposed to mere association. What is agreed upon is that sometimes inferences are made without a full understanding or endorsement of how one made it. In cases of implicit bias this seems to be what it going on. I may well take the fact that the candidate is male as a reason for my belief that he is better qualified for the job without any kind of awareness or endorsement that I believe for that reason. ${ }^{11}$

Once cases like these are brought to mind, nothing seems to rule out that one can represent practical considerations as justifying my belief. I can, for example, see my need for peace of mind as justifying my belief that my child will awaken from surgery. It may turn out that in doing so I am always mistaken in some way, but remember now we are only concerned with whether a practical reason can be one for which I believe, not whether in doing so I am necessarily doing something faulty or irrational. Perhaps beliefs based on such reasons are always improperly based. But an account of the basing relation should not only explain when beliefs are properly based, or when reasons actually justify. In Neta's recent discussion he argues that one of the conditions

\footnotetext{
${ }^{11}$ I have been referring to discussions of inference which is not directly on the topic of the basing relation but the two are very closely connected. In introducing the topic of inference Boghossian (2014) says "My inferring (3) from (1) and (2), it may be thought, is for me to judge (3) on the basis of (1) and (2). Our question about inference, then may be seen as a special topic that is discussed in the epistemological literature under the label the "basing relation." In a more recent discussion he says, "inferring from the judgment that $\mathrm{p}$ to the judgment that $\mathrm{q}$ establishes $\mathrm{p}$ as the epistemic basis for judging $q$, whereas associating $\mathrm{q}$ with p does not." (forthcoming.)
} 
that a theory of the basing relation should meet is that it can explain the difference about when the reason one represents as justifying a belief actually does. On his view, we have seen, one can be mistaken in one's representation of a consideration as reason. In a similar vein, Singh (2018) argues that it is a constraint on an account of motivating reasons that they can fail to be good normative reasons. And, Boghossian is clear that an account of reasoning or inference needs to make room for explaining when one reasons poorly or makes a faulty inference: "Sometimes I reason from a p to a $q$ where $p$ does not support q. That makes the reasoning bad, but it is reasoning nonetheless. Indeed, it is precisely because it is reasoning that we can say it's bad. The very same transition would be just fine, or at any rate, acceptable, if it were a mere association." (forthcoming)

Before moving on to the question of whether beliefs based on practical reasons could be rational, we should note that some argue that the nature of belief rules out the possibility of basing beliefs on practical reasons. Jonathan Adler, for example, was explicit in taking this approach in his Beliefs' Own Ethics. One of his central contentions is that it is a mistake to appeal to "normative notions" in assessing what to believe. He refers to such approaches as "extrinsic," and he argues that this notion is based on a faulty assumption, namely that the concept of belief alone does not fix the ethics of belief. Beliefs, he maintains, have their own "ethics," discovered by a clear analysis of the concept of belief. And such an analysis, he claims, shows that we must believe according to what we take to be evidence and that any mental state based on practical reasons is not really a belief. In arguing in support of his claim quoted above which says that practical considerations cannot be the reasons on which beliefs are based, Kelly makes a similar claim. He says "it is part of the nature of belief that beliefs are states which can be based on epistemic considerations but not on practical considerations." (177).

The weaknesses in these conceptual arguments have been pointed out in a number of recent discussions. (See Rinard (2015, 2017, forthcoming), Leary (2016), McCormick(2015, 2017, forthcoming), Sullivan-Bissett (forthcoming), Reisner $(2009,2014)$, Way (2016)). I do not have space here to reconstruct the various arguments opposing the view that the nature of belief precludes that one can have practical reasons for believing. Common threads in these criticisms are that this "normativist" view requires a revisionist explanation of common practice, that it has an overly narrow view of what counts as a belief, and an overly demanding view of what counts as a reason. Both Susanna Rinard and Jonathan Way, for example, argue that if one takes seriously what counts as reason according to such constitutive views, we would rarely act for practical reasons either. 
If I am right that there is no way, in principle, to rule out basing beliefs on practical reasons, then the argument between those who think some beliefs based on practical reasons can be permissible and those who do not must be conducted at the level which we find in the classic debate between Wilfred K. Clifford and William James. Clifford never denied that it is possible to believe for a practical reason, but he thought it was always wrong to do so. James, on the other hand, argued that under certain conditions believing without evidence is the right thing to do. I now turn to the question of whether it can ever be rational to base a belief on a practical reason.

\section{Distinguishing between good and bad practical reasons}

If there were a way to rule out practical reasons as being reasons which for which one believes then there would not be any need to ask the further question as to whether it is ever rational to do so. Many have claimed that it is a condition on something being a normative reason that it can be a motivating reason. ${ }^{12}$ They have then argued that practical reasons cannot be motivating reasons and therefore cannot be normative ones. I take it that my first section has shown that on many plausible accounts of what it means to base one's belief on a reason that practical reasons can be motivating reasons. But others will say it is a condition on something being a genuine reason, and so a reason upon which a belief can be based, that it can be a good normative one. ${ }^{13}$ This is, for example Jonathan Way's view. He says "Reasons for you to $\varphi$ must be considerations from which you could reason well to $\varphi$-ing." (2016) He then argues that one could never reason well from a practical consideration to a belief. Many agree that even if one could take a practical consideration to be a reason for believing that it is always a mistake to do so; one could never rightly (correctly, properly, aptly) base a belief on it.

What are some features that make a reason a good one, or as some would put it, a genuine "normative" one? While I have no intent to list sufficient, or even necessary conditions of what makes something a good reason, I will discuss three features that are frequently invoked by those who are skeptical about practical reasons being able to be

\footnotetext{
${ }^{12}$ See Rinard (forthcoming) for a discussion of those who argue for this claim.

${ }^{13}$ There are many, for whom the idea of a bad reason does not make sense. If something is genuinely a reason this means that it something like a unit of normativity, counting in favor of some action or belief. According to such views, when one is motivated by a consideration they take to be a reason but that does not support the belief or action, this is not bad reason but no reason at all. I think it is important to maintain the idea that there can be bad reasons. See my for further discussion on this point. Others who agree are Singh (2018) and Hieryonomi (2013)
} 
good reasons for which one can believe. These are that good reasons can provide guidance $^{14}$, that they apply universally, and they can rationalize or justify.

\section{(i) Guidance}

It seems there are two levels at which ordinary evidential considerations can guide. Perhaps there is a sense that I am guided by what I see when I look out my window to the belief that there is a gentle breeze blowing. One might think in such a case my cognitive system is being guided much the way an airplane is guided to the runway; if the guidance succeeds it is brought to the right place. But one might think that reasons should provide guidance in a more robust sense, more like when we turn to a friend or mentor for guidance; they should help advise us on how we ought to believe. When appeals to evidential or alethic considerations offer such guidance it is at the level of offering general rules of belief maintenance such as: "Only believe true propositions" "Do not believe things for which you have no evidence," "Withhold belief without sufficient evidence," or "If one's current evidence is against a proposition, one ought not believe it." When such rules are internalized and we are guided by them, we comply with them automatically. This kind of guidance, or compliance, allows us to communicate, reason, survive and even flourish.

Most of the time believing in accordance with the evidence will be the way to have the best beliefs one can - the beliefs that are the most helpful to oneself and others, the beliefs that reflect the kind of person one wants to be. Most of the time I do not have to think about how I ought to believe, or why I believe as I do. But most of our actions also require little assessment or deliberation; we often operate almost automatically, and we often manage not to violate the rules of prudence or morality. It is when the right course to take is not obvious that deliberation comes in. And the same is true of belief. When I find myself questioning whether or not I should believe something and so deliberating about it, it is precisely because it is not obvious these evidential rules are the only ones that are relevant. In such cases, broadly practical considerations can help guide us.

Take the case of Robert, an alcoholic, who is thinking about whether to commit to the program of alcoholics anonymous. Robert is highly educated and has done extensive research on AA. He knows that some of the central claims made by the program are epistemically suspect; there is a lot of evidence showing they are likely to be false. He also knows that AA is the most successful treatment program. He desperately wants to regain control of his life and knows that the most promising way of doing so is to

\footnotetext{
${ }^{14}$ See Way (2016) for a discussion of why reasons should guide. Littlejohn () questions whether reasons need to offer guidance.
} 
commit to AA which requires believing some of claims lacking evidential support. ${ }^{15} \mathrm{In}$ deliberating about whether to believe, for example, that "being an alcoholic means I have an overpowering chronic disease over which I cannot gain control and that the only way to recover is to turn to God" it is plausible that some of the considerations guiding him would be practical. This seems even more likely if a belief can be based on a reason that is not decisive, that is if it can be partly based on a reason in conjunction with others. In both Rinard and Leary's discussion of how beliefs can be based on practical reasons they point to cases where practical considerations lead you to respond to evidence or epistemic reasons in a way that you would not if such a practical consideration was not present.

Here is an example from Leary:

(Mary) Mary is usually sceptical of other people's testimony and arguments. She didn't give religion much thought growing up, but at college Mary comes to believe that she would be happier if she were to believe that God exists, and that this is a strong reason to do so. While taking a philosophy class, she reads Aquinas's and Anselm's arguments for the existence of God and she befriends a student who tells her about his experiences of divine revelation. While this would usually not be enough to convince Mary (given her sceptical nature), because she recognizes the practical benefit of believing in God as a reason to do so, this causes her to be more swayed by those arguments, and she ends up believing that God exists.

Many will respond to such cases by saying that the belief is actually based on evidential and not practical considerations. But that this evidence would not convince Mary but for such a practical consideration speaks in favor of it being at least one of her motivating reasons. Leary points out that such a case is just like one where one only finds a current piece of evidence convincing because of some other evidential consideration that causes one to see it as convincing. She considers the case of Scully who believes that a suspect isn't human based on a test result showing it is $80 \%$ likely that it is not. Ordinarily, this test result would not be enough to convince her but the fact that she had come across an old X-file stating the subject's tissue sample had nonhuman DNA caused he to view the current evidence as sufficient reason for belief. In

\footnotetext{
15 One may wonder if belief is really needed here. Would something like acceptance be enough? In Jonathan Cohen's (1992) influential discussion of this distinction he is clear that one of the key differences between belief and acceptance is acceptance lacks what he call "credal feelings." Even if one is skeptical about there being any phenomenology associated with believing, given that one can accept for the sake of argument, or because one needs to get something done, one does not need to commit to the truth of the proposition. And it would seem that it is exactly such a commitment that would be needed in the case of AA. For a very interesting discussion of the AA case, and where I found the example see Jenkin (ms).
} 
this case it seems one of the reasons for which Scully believes the suspect is not human is that it is stated in the old X-file report. Similarly, the fact that believing in God would make Mary happier is one of the reasons for which Mary believes. It certainly seems like it is one of the considerations guiding her.

\section{(ii) Universality}

Now let's consider the second feature of good reasons for belief, that they apply universally, some even might say categorically. If I have evidence that supports the truth of a proposition, it seems I have reason to believe it regardless of my desires, inclinations or motivations. And if you find yourself in identical epistemic circumstances, you have the same epistemic reasons that I do, even if our desires and interests vastly differ. I know that you have a reason to believe the earth revolves around the sun without knowing any of your specific aims or goals. But purported practical reasons for belief seem very different. In his discussion of what excludes practical considerations from being reasons for belief Mark Schroeder (2010) notes that such reasons are almost always relativized to a particular subject and context (often involving evil demons or eccentric billionaires) and so are "idiosyncratic" whereas evidential reasons are universal, applying to all believers.

Why is it, though, that evidential reasons seem to have this universality? In his argument for why epistemic rationality and reasons are not instrumental Kelly (2003) recognizes that we talk and act as if reasons that are tied to the general desire of selfpreservation are categorical. I say, for example that you have a reason not to consume a poisonous substance without considering whether you have the goal of living longer or not. I may have no desire to take the medicine, but I still have a reason to do so which is connected to my more general commitment to life. That we can talk about reasons for belief applying to agents independently of their specific circumstances and goals may be because of a similar assumption we make about agents in general. Kelly argues, however, that when it comes to beliefs, we cannot make similar assumptions: "there is simply no cognitive goal or goals, which is plausible to attribute to people generally, which is sufficient to account for the relative phenomena. Individuals do not typically have this goal: believing the truth."

I agree that if one tries to find a specific desire or goal like the goal of acquiring true beliefs, that one will not find that in all agents. But what if the system of epistemic normativity that provides us with reasons to believe is ultimately dependent on its extreme practical value? In a footnote, Kelly considers a wider conception of instrumental rationality based on Williams's (1981) discussion of internal and external reasons which counts a reason as instrumental if it will "advance not only goals which I 
actually hold but also goals which I might reach by a process of sound deliberation from my present 'subjective motivational set.'”

While it seems clear that I can have a reason to believe a particular proposition even if I have no desire to believe (and perhaps even a desire not to believe) that particular proposition, it may well be that in my subjective motivational set, as well as every other agent, one can find a commitment to practices that contribute to human flourishing. I view our system of epistemic norms and reasons as one of those practices, and so these reasons are practical though not narrowly instrumental. When making the case that practical reasons cannot be reasons for belief, "practical" is often used in a narrow sense to mean prudential, in my interest, or advantageous. Invariably monetary incentives are invoked. That we are unable to form a belief against (or without) the evidence when offered money or other incentives to do so is often taken to show decisively that we cannot believe for non-evidential reasons.

While I think there are some beliefs that one cannot believe for some non-evidential reasons, I do not think we can generalize from examples of this kind to the conclusion that non-evidential reasons are never reasons for belief. It is quite likely that there are many actions one could not perform no matter how high the monetary incentive like, for example, killing an innocent person or jumping out the window, but this would not tell us that one can never act for reasons of this kind. To object that one could perform these actions but one chooses not to begs the question. In both cases-that of believing and that of acting - one is being asked to do something that goes against a deeply entrenched view of who one is and what one values.

We can see then that the broad category that can be termed "practical" or "pragmatic" goes beyond the narrowly instrumental. If part of your reason for believing something is that it will contribute to the good in general then this counts as a practical reason. And so we see on this view, that evidential reasons are also practical. And that ultimately their universality is explained by appeal to this their broadly practical value.

\section{(iii) Justification}

Way claims that one cannot reason well from a practical consideration to a belief because good reasoning must correspond to good arguments and that an argument with a practical consideration as a premise will always be a bad argument: "Since the argument 'Believing in God would make me happy, so, God exists' is plainly a bad argument, it follows that the corresponding reasoning is bad." $(2016,815)$ Further, it seems one appropriately bases a belief on a reason if the relation between the two is 
justifying. (Neta 11-12) Here I think we arrive at the core of why it is thought that we cannot properly base our beliefs on practical reasons: it seems obvious to many that only truth-related considerations can justify or support a belief. But why do such considerations make a belief justified or rational, why are they good reasons? This is a question rarely posed and, to some, it may not sound like a coherent question. I have argued $(2015,2017)$ that such reasons are good ones because they provide us with true beliefs, and that the value of true beliefs is broadly practical. ${ }^{16}$ If this is the case then other broadly practical reasons can also rationalize, ones that contribute to flourishing despite their not being evidential.

To try to get a handle on when we consider someone as reasoning well as opposed to reasoning poorly, let's begin by thinking about cases where only evidential considerations are at play. I believe that the ground is wet and this belief is based on my belief that it rained last night. I take it that the fact that it rained last night supports my belief that the ground is wet. Although my belief may turn out to be false, it is likely that I reasoned in an acceptable manner, being guided in some sense by modus ponens. To take an example from David Hume, if you come to believe that "Irishmen have no wit," and the reason you believe this is that all the Irishmen you have met are dullwitted, but you have only met two, then you fail to reason well. This is not, however, because the conclusion is not entailed by the premises. If one's sample size is large enough, we would think it perfectly good reasoning to come to a belief that cannot be construed as a conclusion of a deductively valid argument. If my belief that it never snows in Virginia in July is based on the fact that it never has, this is perfectly acceptable reasoning. I have good reasons to believe it; the reasons offer support for my belief.

Now can practical reasons offer support for my belief, and can we offer a parallel contrast of when they do and when they do not? I'll begin by describing an actual case from my life. One of my very best friends, Susan, will be dying soon from an aggressive sarcoma. She has approached her illness and dying with acceptance despite being one of the heathiest and most active people I have known. Susan is not religious, would not claim to believe in God. She is also highly intelligent and educated; I remember her taking her L-SATs on a whim and achieving such a high score that she

\footnotetext{
${ }^{16}$ I argue (especially in Chapter 2, 2015) that one cannot make sense of a point of view that is distinctly and exclusively epistemic while at the same time retaining the normative force of epistemic reasons. For epistemic goods-such as truth, knowledge, and rationality- to be goods to be promoted, or to provide us with norms to follow, they must be grounded in the practical or moral. Thinking about why we value truth and knowledge reveals that the norms guiding us in what is called the epistemic realm are not isolated from other normative domains.
} 
had top law schools courting her, though was never really going to pursue that path. She believes that when she dies that some aspect of her being will still exist. Of course, people tell her all the time about stories and dreams that provide evidence for such a belief. But none of these form the basis of her belief; they are insufficient support and she would not believe it if these were the only considerations in support. She believes it because it helps to mitigate the concern she has for the pain of her loved-ones. The reasons for which she believes it are broadly practical, connected to love and comfort rather than evidence and truth. Reasons of this kind, and the beliefs they support help provide coherence and meaning. ${ }^{17}$

Susan's belief is quite different from the examples often cited in discussions about practical reasons to belief. As I mentioned earlier, these almost always appeal to incentives to believe, and the kind of practical reason is one of narrow prudential interest. Here is a standard example taken from Alston (1988) "Can you, at this moment, start to believe that the United States is still a colony of Great Britain, just by deciding to do so? If you find it too incredible that you should be sufficiently motivated to try to believe this, suppose that someone offers you $\$ 500,000,000$ to believe it, and you are much more interested in the money than in believing the truth." Alston's main point in introducing such examples was to show we lack direct control over beliefs, but they have also been taken to show that we cannot believe for such reasons.

Such monetary incentives cannot support beliefs in the way that considerations about the value of the belief can, the same value associated with following rules that tend to provide us with true beliefs, namely that they allow for both individual and collective flourishing. The difference between these two cases is similar to the difference between beliefs formed on the basis of a good inductive inferences and those that result from prejudice. In one case I am being guided by a rule of belief maintenance that, if everyone internalizes and follows, will lead to overall flourishing. As noted earlier this does not mean that coming to have any particular belief will be good for a particular person. A particular belief supported by the evidence can be very painful. And holding on to a particular prejudiced belief may serve someone's self-interest, but doing so requires violating rules that lead to true beliefs, or following rules that lead away from them. One can make a similar distinction between beliefs based on practical reasons. If the reasons are such that they do not require one to violate or ignore the rules that tend to lead to truth then they can be justifying. In Susan's case, there is no evidence in

\footnotetext{
${ }^{17}$ For a discussion on how the adaptive purpose of belief is much more than to track truths See McKay and Dennett (2009).
} 
support of the falsity of her belief and so no evidence that requires ignoring or suppressing. ${ }^{18}$

Way's argument against practical considerations being reasons for belief assumes that there is a link between good reasoning and good arguments, and he points out that one place where a pragmatist (meaning someone who thinks practical reason can be reasons for belief) could push back is by denying that link. What I am suggesting here is that these should be de-linked, particularly if arguments are understood as needed to be in propositional form, containing premises and conclusions. I mentioned earlier that many epistemologists take it that the basing relation is trying to capture the relationship that an agent's belief must have to a reason where that reason when stated as a proposition offers justification for the belief when stated as a proposition. That some propositions offer support for others does not tell us anything about what is going on in the mental movements of the agent.

Through our brief tour of different ways of thinking about basing, and reasoning, we can see that it is far from clear that what is going on with these mental movements is best captured by an argument with premises and conclusions. As we saw above, coming to believe, even when such beliefs are inferred from or based on other considerations (which may be other beliefs), can be done in an automatic manner and that to reconstruct what takes place in such mental transitions as something akin to an explicit argument with premises and conclusions is misleading. To ask whether an inference is valid when engaged in a logical proof and to ask whether someone is justified in coming to believe what she believes on the basis of the reasons she does are usually two very different kind of questions. ${ }^{19}$

Think about this piece of reasoning: I have to decide whether I should stay home and grade, or go see my friend's band play. What goes on when I reason about this? It seems I make a kind of list of considerations in favor and opposed to each course of action. Some people even transfer this mental list on to actual paper to assist in their deliberation. If, in the end, I decide to stay home and grade, it seems anything that came up in that list can be a reason for my staying home and grading. But did it function as premise? Would it make sense to think of my deliberative process along these lines:

\footnotetext{
18 In Chapter three of (2015), I discuss, at length, how to distinguish permissible non-evidentially based beliefs from permissible ones.

${ }^{19}$ Boghossian clearly distinguishes between inference as reasoning and inferences as arguments "I am not here talking about inference as argument: that is as a set of propositions, with some designated as 'premises' and one designated as the 'conclusion'. I am talking about inference as reasoning, as the psychological transition from one (for example) belief to another.” (forthcoming)
} 
If I don't grade tonight it will just make things worse for me tomorrow. Things being worse for me tomorrow is something I should avoid. Therefore, I should grade.

I suppose one can reconstruct my reasoning in such a way, though it bears little resemblance to what I think actually goes on in such deliberation. This way of thinking about deliberation fails to capture, for example, all the considerations that were rejected that supported another course of action.

Arpaly and Schroeder, like Siegel, argue that much reasoning is done without deliberation, and that what makes something reasoning "require(s) nothing more than mental transitions that occur because of the logical relations (theoretical entailment, practical entailment, statistical relevance, or the like) between the different attitudes involved." $(2012,238)$ What kind of logical relation is left quite open. Given that they are concerned with both practical and theoretical reasoning, this cannot mean that there must be logical connection holding between propositions. I contend that certain kind of practical reasons can support beliefs while others cannot. And just like in the case of evidential reasons, the details matter.

While Way imagines a pragmatist might want to deny the link he proposes, he offers some points to support the idea that it is "very natural indeed to think there is a tight connection between good reasoning and good arguments." One is that reasoning is expressible, and that it may even be a shared activity. Even if we accept that reasoning is expressible, and I think some of the cases Siegel and others point to suggest otherwise, why think the form of expression must be by stating an argument with premises and a conclusion? When I ask Susan to describe why she believes as she does she does not need to be silent. But what she says will not be of the form Way imagined about someone believing that God exists because it makes him happy. That is, she would not say "Believing that some aspect of my being will continue after I die is comforting and so some aspect of my being will continue after I die." Instead, she would express different feelings she has when contemplating her impending death and the various possibilities of what will occur after. The feeling associated with the belief that some aspect of her being will continue to exist is supportive; it is part of what the belief is based on. This feeling is not that different from what some have deemed an intellectual seeming, or an intuition of truth. Some have referred to such seemings or intuitions of feeling of "rightness." 20 Such feelings can be part of what justifies one believing as one does. To most such a feeling is includes feeling it true. But if a belief can be right, independent of its truth value, then a feeling like the one Susan has can

20 See de Sousa (2008) 
also justify. Something can feel right because it helps one make sense of life, providing coherence and meaning.

\section{Conclusion: Addressing some possible worries}

While I can imagine many objections to the view I put forth, I will not have space here to address most of them. An important assumption for the view I set out in section two is that the value of true beliefs is not intrinsic, but ultimately grounded in its practical value. I have argued for this claim at length elsewhere. ${ }^{21}$

One who wants to resist that idea as well as the conclusions I come to here may say that even if there is some sense in which practical reasons can offer practical justification for beliefs, they cannot offer epistemic justification for belief. As mentioned earlier, this volume is concerned with the epistemic basing relation and so what I am saying here may seem to be largely beside the point.

First, it is important to note that many who are concerned with understanding the basing relation are trying to understand it quite generally; what is the relationship between a particular mental state (intention, belief, hope etc.) and a reason such that we say that one is based on the other. If one is thinking about this more general question then, once the relation is identified it may well turn out that beliefs and practical reasons can be related in that way. To rule out that possibility before we have identified the relationship is unmotivated.

Second, and relatedly, as Way puts it "it would surely beg the question for the evidentialist to insist that reasons to believe be premises of epistemically good reasoning" where such reasoning is defined as those which evidentially support the beliefs they are based on. One thing epistemology should be concerned with is doxastic justification. If it turns out that sometimes one can be doxastically justified when one's belief is supported by a practical reason what would it mean to say that one is not epistemically justified? Perhaps it means that such reasons could not be the kinds of reasons that determine whether one has knowledge. But what rules out that such considerations could bear on knowledge in a significant way? Any theory which allows

${ }^{21}$ See footnote 15 above. I address some worries about this view in responses to Trevor Hedberg's comments here: https://syndicate.network/symposia/philosophy/believing-against-the-evidence/ 
for pragmatic encroachment on knowledge is allowing that practical considerations are not wholly irrelevant to whether one knows. ${ }^{22}$

I want to end by considering a recent challenge Arpaly has raised for anyone who thinks that there are practical reasons to believe. She provides this example:

Imagine this: you have cancer and you do not yet know if the course of chemotherapy you have undergone will save you or not. You sit down at your doctor's desk, trying to brace yourself for news, aware that at this point there might be only interim news - indications that a good or a bad outcome is likely. The doctor says there are reasons to be optimistic. Though you are still very tense, you perk up and you feel warm and light all over. You ask what the reasons are. In response, the doctor tells you about ironclad scientific results showing that optimism is good for the health of cancer patients.

In such a scenario, Arpaly rightly points out, your heart would sink. And she says "A good theory of epistemic and practical reasons should account for the sense of being cheated or mocked that accompanies Sinking Heart cases." Her answer is that the doctor is telling you a falsehood because there are no practical reasons to believe.

When it comes to figuring out what to believe our concern and attention is almost always on whether it is true. And context matters. In the scenario described, it is evident that this is what the patient was asking about, and a doctor who did not get this would be either extremely insensitive or cruel. In another context, hearing about the practical reasons to believe would be entirely appropriate. Think again about Robert and AA. When he reads about the success of the program this provides him with practical reasons to believe AA's tenets; the beliefs (whether true or not) can help him. Here, no sinking feeling need accompany someone telling him there are reasons to believe them even if they are practical. Whether or not his is justified in believing them for those reasons is another matter. If maintaining the belief would require him to ignore or suppress evidence then it may well be unjustified but perhaps, depending on the details, excusable.

\section{References}

\footnotetext{
${ }^{22}$ For arguments supporting the view that practical considerations matter for whether one counts as knowing, see Fantl and McGrath $(2007,2009)$. For a recent overview and critique of arguments in favor of pragmatic encroachment see Roeber (2018), and Gardiner (2018).
} 
Adler, Jonathan. Belief's Own Ethics. Cambridge: MIT Press, 2002.

Alston, William P. "The Deontological Conception of Epistemic

Justification" Philosophical Perspectives 2 (1988): 257-299

Arpaly, Nomy “Epistemology and the Baffled Action Theorist “ (ms.)

Arpaly, Nomy, Schroder, Timothy “Deliberation and Acting for Reasons"

Philosophical Review, Vol. 121, No. 2, 2012

Boghossian, Paul "Inference, Agency and Responsibility," forthcoming in

Reasoning: Essays on Theoretical and Practical Thinking edited by M. Balcerak-Jackson and B. Balcerak-Jackson

“Boghossian, Paul “What is inference? Philosophical Studies, Vol. 169, No. 1, 2014

Cohen, Jonathan L. An Essay on Belief and Acceptance. Oxford: Oxford University Press, 1992.

Comesaña, Juan “Can We Believe for Practical Reasons?” Philosophical Issues (2015), 25, Normativity, 189-207.

de Sousa, Ronald. "Epistemic Feelings," Epistemology and Emotions. G. Brun, U, Doguoglu and D. Kuenzle (eds) Ashgate, 2008

Fantl, Jeremy and Matthew McGrath (2002), "Evidence, Pragmatics and Justification," The Philosophical Review, Vol. 11, No. 1: pp. 67-94._— (2007), "On Pragmatic Encroachment in Epistemology," Philosophy and Phenomenological Research, Vol. 75, No. 3: pp. 558-89. —. (2009), Knowledge in an Uncertain World (Oxford: Oxford University Press).

Gardiner Georgi, 2018. "Evidentialism and Moral Encroachment" In ed. McCain Believing in Accordance with the Evidence: New Essays on Evidentialism. Springer, 169-195.

Jenkin, Robert "Alcoholics Anonymous \& Normative Epistemology: Can believing useful false beliefs be justified?" (ms., masters thesis) 
Kelly, Thomss "The Rationality of Belief and some other Propositional Attitudes" Philosophical Studies 110, 163-196, 2002.

-- "Epistemic Rationality as Instrumental Rationality: A Critique" Philosophy and Phenomenological Research Vol. LXVI, No. 3, May 2003, 612-640.

Korcz, K. 'The Causal-Doxastic Theory of the Basing Relation.' Canadian Journal of Philosophy 30 (2000): 525-50

Leary, Stephanie, "In Defense of Practical Reasons for Belief" Australasian Journal of Philosophy, (2017) 95: 3, 529-542.

McCain, Kevin "The Interventionist Account of Causation and the Basing Relation" Philosophical Studies, (2012) 159 (3): 357-382.

McKay, Ryan T. and Daneil C. Dennet. “The Evolution of Misbelief," Behavioral and Brain Sciences 32 (2009): 493-561.

McCormick, Miriam Schleifer. 2015. Believing Against the Evidence: Agency and the Ethics of Belief. New York. Routledge, 2015.

--- "Responding to Skepticism about Doxastic Agency," Erkenntnis, DOI: 10.1007/s10670-017-9906-2 (2017)

--- "No Kind of Reason is the Wrong Kind of Reason" In ed. McCain Believing in Accordance with the Evidence: New Essays on Evidentialism. (Springer) Forthcoming

Neta, Ram “The Basing Relation” The Philosophical Review (2019) 128 (2): 179-217

Roeber, Blake “The Pragmatic Encroachment Debate" Nous 52:1 (2018), 171-195.

Parfit, Derek, "Rationality and Reasons," in Dan Egonsson et al., eds., Exploring Practical Philosophy (Burlington, VT: Ashgate, 2001), pp. 17-39.

Piller, Christian, "Normative Practical Reasoning," Proceedings of the Aristotelian Society, Suppl. Vol. XXV, 1 (2001): 195-216 
Rinard, Susanna "Against the New Evidentialists" Philosophical Issues 25, 2015. doi: 10.1111/phis. 12061

--- "Believing for Practical Reasons", Nous, forthcoming.

Schroeder, Mark "Value and the Right Kind of Reason," in R. Shafer-Landau, ed., Oxford Studies in Metaethics 5, Oxford: Oxford University Press, pp. 25-55 (2010)

Siegel, Susanna, "Inference Without Reckoning" forthcoming in Reasoning: Essays on Theoretical and Practical Thinking edited by M. Balcerak-Jackson and B. Balcerak-Jackson

Singh, Keshav "Acting and Believing Under the Guise of Normative Reasons" Philosophy and Phenomenological Research, 2018.

Sullivan-Bissett, Ema forthcoming: 'Explaining Doxastic Transparency: Aim, Norm, or Function?' Synthese. DOI: 10.1007/s11229-017-1377-0

Sylvan, Kurt. “Epistemic Reasons II: Basing." Philosophy Compass 11 (7):377-389 (2016)

Way, Jonathan "Two Arguments for Evidentialism" The Philosophical Quarterly (2016) 66 (265): 805-818.

Williams, Bernard 1981: "Internal and External Reasons", in his Moral Luck. (Cambridge University Press, Cambridge), pp. 101-113. 